\title{
An integrated modeling framework to evaluate water allocation strategies in the Broken catchment, Victoria
}

\author{
B. George ${ }^{1}$, R. Adams ${ }^{1}$, T. Ramilan ${ }^{2}$, J. Costelloe ${ }^{1}$, M. Sammonds ${ }^{1}$, G. Vietz ${ }^{1}$, \\ B. Farquharson ${ }^{2}$, A. Western ${ }^{1}$ \\ ${ }^{1}$ Department of Infrastructure Engineering, The University of Melbourne, Parkville, VIC, 3010 \\ ${ }^{2}$ Dept. of Agriculture and Food Systems, The University of Melbourne, Parkville, VIC, 3010
}

Email: biju@unimelb.edu.au

\begin{abstract}
River basins in Australia face increasing competition between economic and environmental water use. The competition for water for agricultural, urban, industrial and ecological uses is exacerbating due to increasing climate variability, urbanization, economic activity and population. This paper presents an integrated modelling framework for water resources planning and management that can be used to carry out an analysis of alternative policy scenarios for water allocation and use. The integrated modelling framework consisted of farm economics, hydrology, ecology and water allocation. The framework was implemented in the Broken catchment, Victoria where there is significant competition between agriculture and the environment.
\end{abstract}

The first step towards developing a water allocation model is to take account of the current resource situation, its spatial and temporal distribution and any recent trends. The hydrologic model AWBM, a lumped model running on a daily time step, was calibrated and validated using data from two gauges in the catchment, using the GLUE framework to evaluate the model performance and estimate upper and lower bounds to the predicted flows. Parameter sets obtained from the calibration were used to estimate the ungauged inflows in the catchment. The catchment was split into $17 \mathrm{sub}$ catchments and 5 reaches. Two water availability scenarios were simulated-water availability based on the historical climate, and under a projected drier and hotter climate representative of 2030, similar to the 2030 dry climate scenario used in the CSIRO Murray Darling Basin Sustainable Yields (MDBSY) study.

Irrigation water is used the Broken catchment for improved pastures in the dairy industry, perennial horticulture (orchards and vineyards) and irrigated cropping. The irrigation demands were quantified through representative farm models solving for profit maximising water use, and scaled up to the catchment level according to the land-use areas.

Changes in water quantity and quality can have significant effects on the natural ecosystem of rivers. To estimate environmental flow requirements of the Broken system an expert panel developed a set of 17 environmental objectives and associated flow rules. These flow rules were modelled in $e F l o w$ predictor to estimate the augmented flow to meet the rules.

In this research, allocation of water to meet environmental and irrigation demands is based on the integration of water supply and demand through a network allocation model Source Rivers, developed by the eWater CRC. Source Rivers model uses a node-link network to represent the river basin and it works on a daily time step and has the capability to route the flows in the system.

The framework was implemented in the Broken catchment, Victoria and was used for modelling different water allocation scenarios to analyse the tradeoffs between agricultural and environmental outcomes

Keywords: River basin, water allocation, economics 


\section{INTRODUCTION}

Climate change is expected to increase the pressure on water resources, either by shifting directly hydrological cycles and spatial and temporal availability of water for irrigation due to changes in precipitation patterns or by increasing agricultural water demand due to temperature increases and higher frequencies of drought events. Climate change together with growing water diversions for economic use are increasingly stressing many river basins around the world, compromising the integrity of aquatic ecosystems as minimum sustainable flows to maintain the environment is not provided. In order to cop up with the future water scarcity by developing appropriate infrastructure and management strategies require accurate projections of water supply and demand.

Most of the rivers in the southern Murray Darling face intense competition between agriculture and the environmental water use (Chartres and Williams, 2006; Western et al. 2011). The water available for agriculture may be reduced in the future to preserve the relative balance between the two demands. In order to minimise the impacts on both agriculture and environment innovative planning and management of water resources is essential. This paper presents an integrated modelling framework for water resources planning and management that can be used to carry out an analysis of alternative policy scenarios for water allocation and use.

The integrated modelling framework consisted of farm economics, hydrology, ecology and water allocation. The framework was implemented in the Broken catchment, Victoria.

\section{THE STUDY AREA}

The Broken River is one of the tributaries of the Goulburn River in north-eastern Victoria, covering an area of approximately $2500 \mathrm{~km}^{2}$ to the lowest gauging station at Orrvale (Figure 1). The upper catchment of the Broken River is regulated by Lake Nillahcootie with a storage capacity of $40 \mathrm{GL}$ and was constructed in 1967. Water is released from this storage over the year to meet the downstream demands (mainly irrigation, stock and domestic). Total annual entitlement of surface and groundwater in this catchment is approximately $31 \mathrm{GL}$ of which about $10 \%$ is from groundwater. The mean annual rainfall of the catchment is $800 \mathrm{~mm}$ and average annual streamflow was estimated at $210 \mathrm{GL}$, with an uneven distribution in space and time. Average annual PET was estimated at $1220 \mathrm{~mm}$ (Adams and Western, 2010). Lake Mokoan was an off-stream storage located approximately $50 \mathrm{~km}$ downstream of Lake Nillahcootie that has been recently decommissioned into a wetland. The storage capacity of this lake was 362 GL.

Irrigation water is used the Broken catchment for improved pastures in the dairy industry, perennial horticulture (orchards and vineyards) and irrigated cropping. Dryland agriculture in the catchment consists of rainfed livestock and cropping activities. The area of irrigated agriculture is only $2 \%$ of total agricultural land in the Broken catchment (Farquharson et al. 2011). The majority of the irrigation area in this catchment is located below Casey's weir and along the Broken Creek.

\section{THE INTEGRATED MODELLING FRAMEWORK}

Water resource systems are complex systems with many interactive activities. The complexities involved in water allocation and use in a river basin require a whole-of-system approach to understand and analyze the behavior of these

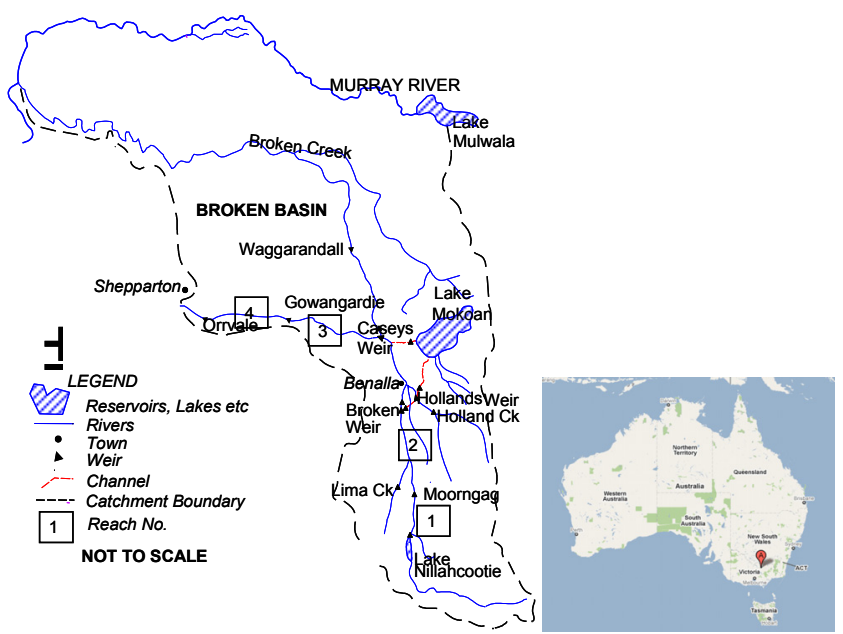

Figure 1. Map of Broken catchment. systems under different policies (George et al. 2011). A better understanding of water supply and demand, and its economic value, is essential if alternate policies are to be developed. The framework consists of three main components (Figure 2):

- A resource assessment of the supply;

- An estimation of water demand both agricultural and environmental; 
- An allocation model to distribute water to different demand centers; and,

- An economic assessment based on Gross Margin Analysis.

\subsection{Hydrologic Analysis}

The supply domain is primarily focussed on surface and groundwater assessment. The first step towards this is to take account of the current resource situation, its spatial and temporal distribution and any recent trends. This can be achieved by detailed modelling of catchments using hydrologic modelling tools. A historical hydrologic modelling and stream flow simulation was carried out at catchment scale to identify the most important components of the water balance. A monthly

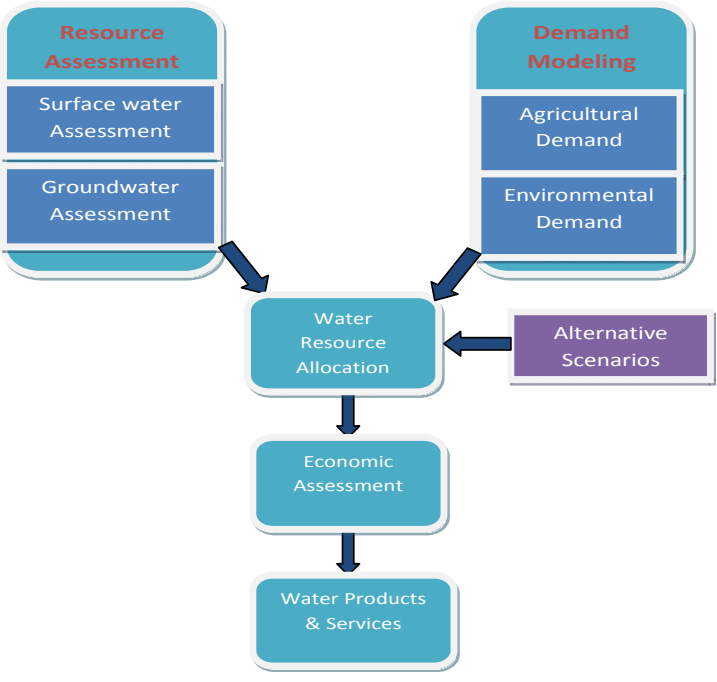

Figure 2. Conceptual map conceptual rainfall-runoff model AWBM can be used to model the rainfall-runoff process at key supply nodes in the catchment (www.toolkit.net.au). The losses from the system (seepage and evaporation) need to be estimated together with stream-aquifer interactions to estimate the recharge and discharge from surface to the groundwater system.

The hydrologic model AWBM, a lumped model running on a daily time step, was calibrated and validated using data from two gauges in the catchment (Lima and Holland creek). Forcing data (rainfall and PET) data for the modelled period were obtained from the BOM gridded data covering the subcatchments, and SILO data from three met stations in the catchment respectively. The model was calibrated for the period 19872006 on Holland and Lima creeks and parameter sets were obtained. These parameter sets have also been incorporated in a Source Catchments model of the entire Broken system which enables different climate scenarios to be run through the model. The catchment was split into 17 subcatchments and 5 reaches.

Two water availability scenarios were simulated - water availability based on the historical climate, and under a projected drier and hotter climate representative of 2030 , similar to the 2030 dry climate scenario used in the CSIRO Murray Darling Basin Sustainable Yields (CSIRO, 2008) study.

\subsection{Water Demand}

Water demand estimation is based on agricultural, social and economic activities in the catchment. A variety of techniques can be used to estimate water demand ranging from simple projection to sophisticated modelling. The main users of water in the broken catchment are agriculture and environment. The techniques used to estimate these demands are described hereunder.

\section{Agriculture}

Irrigation water is used the Broken catchment for irrigating pastures, perennial horticulture (orchards and vineyards) and irrigated cropping. Dry land agriculture in the catchment consists of rainfed livestock and cropping activities. The area of irrigated agriculture as a proportion of total agricultural land in the Broken catchment is in the order of $2 \%$.

A number of approaches have been applied to modelling demand. Some of these include time series approaches, quasi economic approaches or based on crop water requirements. Program for Regional Irrigation Demand Estimation (PRIDE) is a commonly used tool for the estimation of irrigation demand in Victoria, Australia (DSE, 2007). It estimates the irrigation requirements of crops using the Penman-Monteith approach based on climate, crop culture and knowledge of traditional farming practices. The model has the capability to estimate crop water requirements by water year and user has the capability to specify the start date of irrigation season. The model was used to estimate irrigation requirement of Broken catchment. 


\section{Environment}

Changes in water quantity and quality can have significant effects on riverine ecosystems. Infrastructure for the storage and diversion of water to meet growing consumptive and urban uses and contamination of water bodies through agricultural runoff impacts on ecological condition of the river. The actual impacts of current water management on ecosystems are not well quantified in the Broken system.

The environmental water requirements were estimated based on the following steps (Western et al. 2011, Farquharson et al. 2011): objective setting, flow rule development, flow rule prioritization, and development of environmental flow regimes using the flow rules.

An expert panel approach was used for environmental objective setting and flow rules development: incorporating fish and invertebrate ecology, vegetation and nutrient dynamics, and geomorphology. The approach is deterministic (and 'bottom up') and relies on linking environmental objectives with hydrology: resulting in environmental flow 'rules' explicitly linked to each objective. Hydraulic models (HEC RAS) were used to quantify magnitude for specific inundation, velocity or shear stress targets desired. Hydrologic data were used to quantify natural variation in flow components and the impacts of a regulated regime and inform rule setting. Hydrologic data were obtained through AWB Model for an extrapolated 100 year series for both 'natural' and regulated conditions.

Each of the seventeen environmental flow rules consists of the following:

- Objective focus e.g. fish, invertebrates, vegetation, nutrients, geomorphology;

- Habitat type impacted e.g. channel bed, slack water, riffle/run, floodplain;

- $\quad$ Timing e.g. spring, summer;

- Magnitude of flow e.g. X ML/d;

- Frequency of flow e.g. continuous or Y times per season;

- $\quad$ Duration e.g. $Z$ days; and

- Rationale and mechanism e.g. turnover of substrates to reduce smothering through adequate shear stress.

Rules were prioritized, based on a subjective assessment by the entire panel, and categorized into three groups: low, medium and high risk to the environment. These flow rules were then modelled using eFlow predictor (eWater CRC, www.ewater.com.au) to estimate the augmented flow to meet the environmental flow requirements. The augmented flow essentially identifies the demand at compliance points required to maintain a minimum level of ecological health in the Broken River.

\subsection{Water Allocation}

Water allocation models allocate available water to individual demand centers in space and time within a river basin. By using these models policy makers can gain insight into the consequences of policy changes and changes to physical infrastructure on water allocations. Commonly used models for water allocation modelling in Australia include REALM (Perera et al. 2007), Wathnet (Kuczera, 1992) and IQQM (Hameed and Podger 2001). The 'Source Rivers' tool which is currently under development by the eWater CRC partners using The Invisible Modelling Environment (Rahman et al., 2003) is emerging as a replacement for these models. In this research, the modelling of river system is based on the integration of resource availability and water demand using 'Source Rivers'. It can assess long-term impacts of water resources policy on system storages, flows and water shares. The model uses a node-link network to represent the river basin where nodes represent the physical units such as reservoirs, aquifers, townships, agriculture and industries and links represents the carriers which connects the nodes. The model works on a daily time step and has the capability to route the flows in the system. To enable the simulation of water allocation, different elements of the water supply and demand system and their spatial relationships needs to be characterized for the river basin.

Three main steps in the simulation of a regulated river system are (Welsh and Podger, 2008):

- A resource assessment of the supply available in the river and storages and an estimation of water demand. Both consumptive and non-consumptive users can be modeled using 'Source Rivers'. Agricultural demands can be estimated using models like PRIDE or IQQM crop model or can be input as a time series demand.

- The amount of water required to be released from the storage to meet the orders along the system is calculated by cumulating daily water order from both consumptive and non-consumptive uses after allowing for travel time, losses/gains in conveyance and flow constraints. 
George et al., An integrated modelling framework to evaluate water allocation strategies

- Reservoir releases are routed down the system by supplying water to different water users based on the orders placed, by carrying out a water balance at each node where water is either extracted or added.

A 'Source Rivers' model was set up for the Broken catchment. Agricultural water demand was estimated using PRIDE model. Source Rivers has the capability to integrate environmental flows requirements in water allocation scenarios. The time series of environmental demands were estimated using eFlow predictor and used as an input.

\subsection{Economic Analysis}

Farm economic models were built for irrigated dairy, perennial horticulture and irrigated cropping. These models included crop diversity in orchards and complicated management on dairy farms, previous modeling exercises only used broad categorization. These models include different water use technologies, alternative cropping, various pasture pool constraints, crops and conserved feed, feed transfers and reconciliations, livestock numbers, limits to crop and pasture areas and volumetric allocation of water.

In economic modeling total farm gross margin (TGM) was defined as the difference between returns from agricultural produce plus produce sales and variable costs. The objective function in the model is the maximization of the total gross margin for the farm and subject to constraints on water availability and other resources. The farm models were built using GAMS modeling language and solved using a linear programming algorithm. The outputs of this optimization process were the optimal livestock and cropping system, the corresponding TGMs, demand for irrigation water use. The economic model output was then scaled up to the basin level to assess the economic impact of water allocation scenarios.

The economic model assumes that farmers pursue short run profit maximization and perfect subsituability of water among enterprises. Differences occur in the economic use of water across the catchment has only considered at in broad farm types. In reality farms exhibit considerable heterogeneity in all important variables from managerial ability and attitudes to soil type and use of inputs, to profitability and risk aversion. Because of data limitations these issues has not been modelled. Considering these could have led to differences occur in the economic use of water across the catchment. However given relatively small extent of irrigated land use, we can't expect reasonable variation in geophysical features. Extra value of representing risk aversion is commonly very little for the effort (Pannell, Malcolm, \& Kingwell, 2000).

\section{RESULTS AND DISCUSSION}

The water allocation model was run on a daily time step and it generates several outputs including volume ordered and ordered volume supplied for each demand node for each day of the simulated time series. These values were then aggregated to calculate the annual values. The annual figures were then used to develop the frequency analysis and reliability of supply for each event. The level of supply security at different levels of assurance and shortfall and its recurrence interval are useful information to water resources managers to support allocation decisions.

The simulations were carried out for two scenarios: Historical climate (Business as Usual) and 2030 dry scenario. The results suggest that the shortfall occurs in both agriculture and environmental demand centres but were higher for environment compared to agriculture. This is mainly because high priority was assigned to agriculture compared to environment. Also the environmental demands were much higher than those of agriculture. The analysis suggests that the system can supply only $13.5 \mathrm{GL}$ to agriculture at $90 \%$ reliability, which is approximately $80 \%$ of current entitlement. Under a climate change scenario the supply to agriculture at $90 \%$ reliability will reduce to $8 \mathrm{GL}$ which is approximately $50 \%$ of current entitlement. In this situation there is a need to develop alternative strategies to 'do more with less water'.

Figure 3 shows the allocation volumes associated with different levels of assurance and expected shortfall frequencies for the historical climate and 2030 dry scenario. There is a sharp rise in shortfall between 2 and 10 years of recurrence interval at both agricultural and environmental demands indicating that there high probability of water shortages occurring at short intervals in this catchment. 
The volume of water allocated to agriculture and environment under the 'dry scenario' was found to be less than that of historical climate at all assurance levels but more significant at low assurance levels. In order to minimize the impact on agriculture and environment in a drying climate, we need to explore the possibility of innovative water management techniques which include conjunctive management of surface and groundwater and co-releases to satisfy both demands.

The irrigation water orders are now satisfied as single demands. If the timing of irrigation and environmental demand coincide, the same water could be used to meet both these demands. Co-release would result in water savings and in improved economic and ecologic outcomes. An analysis of one year demand data concluded
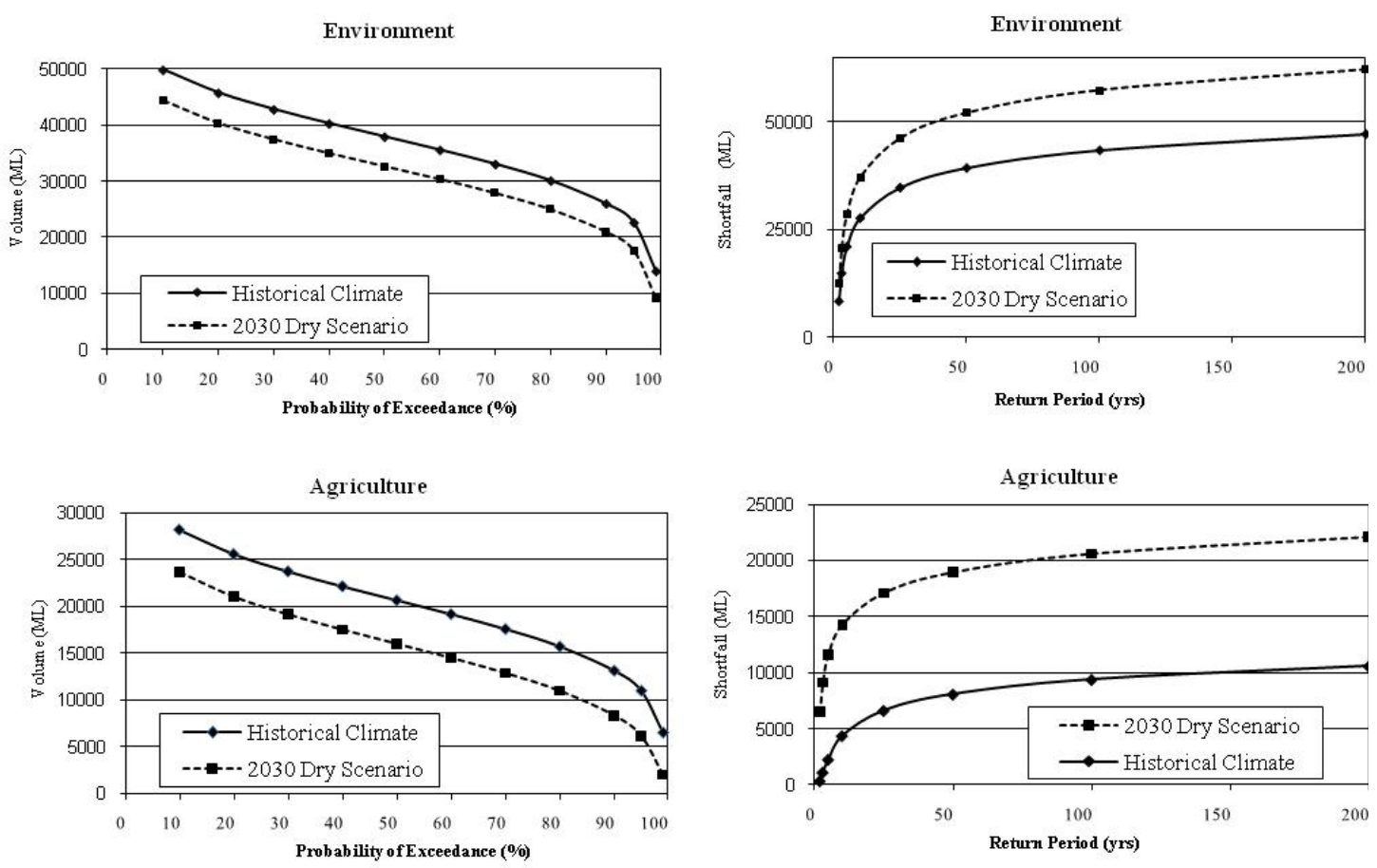

Figure 3. Comparison of volume supplied at different levels of assurance and shortfall at different return periods

that the environmental demands at the start of the irrigation season (July to Sept) is far more than the irrigation demand. But co-releases can save lot of water from October to January. The analysis will be extended to evaluate alternative scenarios like conjunctive management of surface and groundwater, using wet lands for temporary storages and crop diversification. The economic analysis of these scenarios is currently in progress.

\section{CONCLUSIONS}

In this paper an integrated modelling framework that can be used to assess the impacts of alternative water allocation scenarios is presented. The framework was based on integrating hydrology, water allocation and economics. This study focuses on the Broken catchment located in southern Murray Darling basin.

The modeling framework was used to analyse two climate scenarios: Historical climate and 2030 dry scenario. Shortfalls are indicative of a need for policy-makers to strategize and explore options with respect to alternate water allocation scenarios. The modeling results suggest that the shortfall occurs in both agriculture and environmental demand centres but were higher for environment compared to agriculture. The volume of water allocated to agriculture and environment under the 'dry scenario' was found to be less than that of historical climate at all assurance levels which is clearly indicating the need for developing strategies to minimize the impact of climate change. 
George et al., An integrated modelling framework to evaluate water allocation strategies

\section{ACKNOWLEDGMENTS}

The Farms Rivers and Markets Project is an initiative of Uniwater and funded by the National Water Commission, the Victorian Water Trust, The Dookie Farms 2000 Trust (Tallis Trust) and the University of Melbourne. The project is supported by the Departments of Sustainability and Environment and Primary Industry, the Goulburn Broken Catchment Management Authority and Goulburn-Murray Water.

\section{REFERENCES}

Adams, R. and Western, A. (2010). Using uncertainty analysis to improve estimates of water availability for a regulated catchment in southern Australia. International BHS conference, New Castle U K.

Chartres, C. and Williams, J. (2006). Can Australia overcome its water scarcity problems. Journal of developments in sustainable agriculture, 1: 17-24.

CSIRO. (2008). Water availability in the Goulburn-Broken. A report to the Australian Government from the CSIRO Murray-Darling Basin Sustainable Yields Project. CSIRO, Canberra, ACT, Australia, pp 132.

Department of Sustainability and Environment. (2007). PRIDE user manual from http://www.water.vic.gov.au/_ data/assets/pdf_file/0020/52463/pride-user-manual.pdf.

Farquharson, B., Ramilan, T., Stewardson, M., Beverly, C., Vietz, G., George, B., Dassanayake, D. and Sammonds, M. (2011). Water sharing for the environment and Agriculture in the Broken catchment. 55 Annual AARES National Conference, Melbourne, pp 1-20.

George, A., Malano, H., Davidson, B., Hellegers, P., Bharathi, L. and Sylvian, M. (2011). An Integrated Hydro-Economic Modelling Framework to Evaluate Water Allocation Strategies I: Model Development, Agricultural Water Management, 98(5): pp 733-746.

Hameed, T. and Podger, G. (2001). "Use of IQQM simulation model for planning and management of a regulated river system", IAHS Red Book 2001, pp 83-89.

Kuczera, G. (1992). "Water supply headworks simulation using network linear programming." Adv. In Eng. Soft., 14, pp 55-60.

Pannell, D. J., Malcolm, L. R. and Kingwell, R. S. (2000). Are we risking too much? Perspectives on risk in farm modelling. Agricultural Economics, 23(1): pp 69-78.

Perera, B.J.C., James, B., and Kularathna, M.D.U. (2005). Computer software tool REALM for sustainable water allocation and management. Journal of Environmental Management, 77, pp 291-300.

Rahman, J.M., Seaton, S.P., Perraud, J.M., Hotham, H., Verrelli, D.I. and Coleman, J.R. (2003). It's TIME for a new environmental modeling framework. Proceedings of MODSIM 2003, 4: pp 1727-1732.

Welsh,W.D. and Podger, G.(2008). Australian Hydrological Modelling Initiative: River System Management Tool (AHMI: RSMT) Functionality specifications, e-water CRC.

Western, A., Gawne, B., Bond, N., Costelloe, J., Dassanayake, K., Farquharson, B., George, B., MacNally, R., Nielson, D., Ning, N., Ramilan, T., Sammonds, M., Stewardson, M. and Vietz, G. (2011). Mile stone 6 discussion paper on Rivers, Groundwater and Environmental targets. Farms, Rivers and Market project. 